Article

\title{
Studying During the COVID-19 Pandemic: A Qualitative Inductive Content Analysis of Nursing Students' Perceptions and Experiences
}

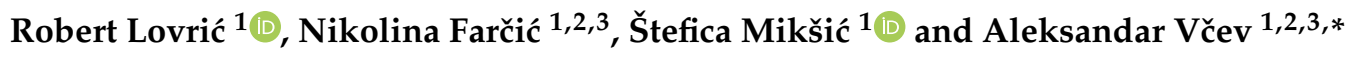 \\ 1 Faculty of Dental Medicine and Health Osijek, Josip Juraj Strossmayer University of Osijek, \\ 31000 Osijek, Croatia; rlovric@fdmz.hr (R.L.); nfarcic@fdmz.hr (N.F.); smiksic@fdmz.hr (Š.M.) \\ 2 University Hospital Centre Osijek, 31000 Osijek, Croatia \\ 3 Faculty of Medicine, Josip Juraj Strossmayer University of Osijek, 31000 Osijek, Croatia \\ * Correspondence: avcev@fdmz.hr; Tel.: +385-31-399-600
}

Received: 6 June 2020; Accepted: 17 July 2020; Published: 21 July 2020

\begin{abstract}
Coronavirus disease 2019 (COVID-19) is the latest pandemic with a high rate of morbidity and mortality worldwide. Crises like these can harm the academic functioning and psychophysical health of nursing students. With this qualitative study, we aim to explore how students perceive the COVID-19 crisis and what their personal experiences were while studying during the global pandemic. In the study, data saturation was achieved after analyzing the reports of 33 undergraduate nursing students, using the inductive thematic saturation method. Data were collected using an online form, which students filled out, describing their perceptions and experiences. Qualitative inductive content analysis of students' reports resulted in 29 codes, indicating different student perceptions of the efficiency of state institutions in crises. All students described the spread of misinformation on social networks and the risky behavior of the population. Most are afraid of infection and worried about the well-being of their family, so they constantly apply protective measures. Students recognize their responsibility to the community and the importance and risks of the nursing profession. They also describe negative experiences with public transportation and residence in the student dorm. The fear of possible infection in the classroom is not significant, however, students are afraid of the clinical settings. Thirteen students reported difficulty in concentrating and learning, while all students praised teacher support and faculty work in this crisis.
\end{abstract}

Keywords: COVID-19; coronavirus infections; pandemics; qualitative research; nursing students; student experiences; student perceptions; student safety

\section{Introduction}

Coronavirus disease 2019 (COVID-19) is the latest infectious disease to develop rapidly worldwide [1], to the extent of a severe global pandemic [2]. The etiologic agent of COVID-19 is the severe acute respiratory syndrome coronavirus 2 (SARS-CoV-2), which emerged in Wuhan, China [1,2]. According to the World Health Organization (WHO), from December 2019 to mid-April 2020, more than 2 million COVID-19 cases and more than 100.000 deaths have been confirmed worldwide, including more than 200 countries [3]. In Europe alone, more than 1 million people were infected during this period. In Croatia (CRO), the first case of COVID-19 was identified on February 25th, 2020, after which the number of confirmed cases increased steadily.

There is still a lack of experience about COVID-19 in the world and there are many ongoing scientific studies [4]. SARS-CoV-2 is known to possess potent pathogenicity and transmissibility [4]. Patients with severe COVID-19 tend to have a high viral load and a long virus-shedding period [5]. 
However, the transmission of infection is also possible from asymptomatic patients [6]. The risk of transmitting a disease to healthcare professionals is unavoidable in these situations $[4,7,8]$, which is also a serious threat to nursing students [9], who are very quickly becoming aware of their risk of infection [10,11]. For example, in Italy, more than 15,000 health workers were infected with SARS-CoV-2 by mid-April, and more than 19,000 were tested positive in Spain [12]. Nursing students are a direct link between hospitals and universities, with the capacity to act as a conduit of pathogens to large, susceptible populations [9]. These facts are very stressful for students, with possible negative implications for their studies and their psychophysical health [11]. Therefore, universities need to respond promptly and appropriately to protect their students by preventing the spread of this infectious disease into the university community during an epidemic [9]. Due to the COVID-19 pandemic, on 16 March 2020, regular university classroom teaching, as well as student training in the clinical settings were discontinued in Croatia. The project of live distance lectures delivered to students at home was started by creating online virtual classrooms. Thus, the possibility of direct contact of nursing students with patients, students and faculty members is blocked, which is a very effective method of protecting students and the entire community [13].

Given that COVID-19 is a new pandemic, a review of the related literature has found no currently available relevant study that describes the perceptions and experiences of nursing students during the COVID-19 pandemic. Existing, mostly quantitative studies have described the insights, perceptions, and experiences of nursing students concerning an earlier Middle East respiratory syndrome coronavirus (MERS-CoV) epidemic that occurred in Saudi Arabia in 2012 [14]. Thus, students from Al-Ghad International College for Applied Medical Sciences from Saudi Arabia considered coronavirus to be a very deadly virus, dangerous for humanity, and that preventive measures of isolation are necessary [15]. Additionally, they hold that MERS-CoV is a fatal disease, and that healthcare professionals are at high risk for infection. Students from two other Arab studies came to the same conclusions $[10,16]$. Qassim University students believe that transmission of the disease can be prevented following universal precautions given by WHO [17]. However, nursing students often find that the population is unaware of the transmission of the viral infection and the severity of the situation, and does not act on the recommendations of state institutions $[8,15,17]$. The results of a Korean study suggest a positive correlation between nursing students' attitudes towards infection prevention measures and the frequency of their use [18]. Furthermore, several relevant studies describe sources and ways of informing students during the epidemic and possible arising difficulties $[8,9,11,15,17]$. Thus, students most often use the Internet, TV, and radio for information purposes [15,17], social networks such as Twitter [8,9], or they obtain information from college sources, official health authority statements [11], or from friends and family [9]. According to WHO, the world is currently affected by massive "infodemic" (info[rmation] + [epi]demic), an over-abundance of information, which involves the excessive dissemination of false information associated with COVID-19 [19]. Students are often exposed to a lot of misinformation in these situations, which can cause psychological distress $[9,11]$. Al-Rabiaah et al. [11], in their recent quantitative study, described the perceptions and determinants of psychological distress of students from different health professions, during the MERS-CoV epidemic. Their results indicated a high level of stress in all students, which had negative consequences on students' learning and academic achievement, as well as on their overall psychological health [11].

The previously mentioned studies indicate the importance of examining the perceptions, feelings, and attitudes of nursing students during major epidemic crises, to provide adequate measures of student protection and support promptly. Unfortunately, the available literature still does not offer enough in-depth analyses of nursing students' experiences during pandemics (especially not for COVID-19), which could significantly affect the level of global understanding of the seriousness of nursing students' needs, problems, and difficulties in extreme crisis situations. Therefore, the purpose of our study is to fill this gap by providing the results of a qualitative inductive analysis of the free-form (undisturbed) nursing students' descriptions of their own perceptions, emotions, expectations, and behaviors, 
while studying during the COVID-19 pandemic. Thus, we expand the existing global knowledge about the psychological and behavioral aspects of nursing students' functioning in crisis situations.

Thus, our study sought to explore the perceptions and experiences of Croatian BSc nursing students regarding the new COVID-19 global pandemic, three days before the Croatian Government decided to temporarily close all educational institutions in the country and implement remote learning. Thus, by inductive qualitative analysis of students' experiences, we are seeking to gain a better and deeper understanding of the possible impact of the pandemic on their study process. In particular, the study focused on providing answers to the following questions: (1) how students perceive the COVID-19 crisis; and (2) what their personal experiences were while studying during the global COVID-19 pandemic.

\section{Materials and Methods}

\subsection{Design and Theoretical Framework of the Study}

This qualitative study was conducted in Osijek on March 13th, 2020, seventeen days after the first identified case of COVID-19 in CRO, and three days before the temporary cancellation of regular university teaching. According to WHO [20], on the day the study was conducted, sixteen COVID-19 cases were identified in CRO, with no fatalities, and 132,758 COVID-19 cases and 4955 deaths were confirmed worldwide. The study is designed to accurately describe the phenomenon of students' experiences, using a generally accepted method of conventional inductive content analysis [21]. This type of design is usually appropriate when there are only few previous studies and grounded theories describing the phenomenon in question, or when the phenomenon itself is fragmented [21,22]. Therefore, this study does not have one strict theoretical starting point. However, given the aim of the study and the subsequently identified relations between categories and subcategories [21], certain results can be considered in terms of cognitive theories of emotions [23], fear, and stress [24]. Other results can be interpreted from the perspective of humanistic nursing theories and theories of professional identity in nursing, such as Erickson's psychosocial theory [25] and personality type theory [26,27]. Thus, using a conventional approach to content analysis, relevant concepts and theories are addressed in the discussion section of the study [21].

\subsection{Participants}

The participants in the study were 33 BSc nursing students, from the Faculty of Dental Medicine and Health in Osijek, Croatia. There was 29 female (88\%) and 4 male (12\%) students, with a mean age of 21 years. Purposive sampling, based on intended research outcomes, was performed according to the defined criteria [28]. The sample size was further determined based on informational needs and using a model of inductive thematic saturation, as a criterion for discontinuing data analysis $[29,30]$. The inductive thematic saturation applied in this study focused on the identification of new codes or themes. In such an approach, saturation appears confined to the level of analysis and its implication for data collection is at best implicit [30]. The saturated number of 33 respondents in this study is consistent with other similar relevant studies and descriptions, which suggests that, to obtain a detailed insight into the phenomenon studied in such studies, the data should be based on about 1 to 30 participants [21,22,28-32]. Smallest acceptable sample size of interviews in all qualitative research is elsewhere determined at around fifteen, but not exceeding fifty respondents [32].

The inclusion criteria for participation in the study were: (1) enrollment in a BSc Nursing Studies program; (2) voluntary student participation in the study; and (3) written student reports, following the two major research questions and the researcher's instructions. Of the 37 received student reports, four were excluded from further analysis, because they were not substantively completed. 


\subsection{Data Collection}

Data were collected using the online form, which included details of the study, additional guidelines, and two major research questions. It was sent via e-mail from the students' office to all eligible participants. Online data collection has been applied to minimize any potential risks, and to maintain a higher degree of confidentiality [33]. Due to the anonymity of participants, the form included an encrypted ID code (a combination of letters and numbers). In order to minimize the biases of researchers and participants, and to maintain neutrality, researchers were not otherwise directly involved in working with participants, and any suggestions from researchers were avoided. The questions are formulated considering potential biases, and in a manner that allows the participant to feel accepted, no matter what the answer is. Following Bengtsson [29], non-suggestible, open-ended written questions were used to further encourage students to express their thoughts. Writing time and amount of text were not limited. Open-ended written questions provide students with freedom of writing, a secure flow of thoughts, and a detailed description of their perceptions and experiences, which cannot be achieved using structured questionnaires with preconceived questions and provided answers [29]. Additionally, students stated that the written form of expression is more appropriate than oral, because it does not cause anxiety and gives them more time to think and respond, which further reduces the possibility of wrong answers.

Thus, students were asked to describe (1) their perceptions of the COVID-19 crisis and (2) their experiences while studying at the time of the global COVID-19 pandemic. All students received the final coded data for additional verification of responses [22].

\subsection{Data Analysis}

In this qualitative study, an inductive approach was applied, using a conventional content analysis of students' written reports [29]. Conventional content analysis is a research method for the subjective interpretation of the text data content through the systematic classification process of coding and identifying themes or patterns. Content analysis can be used as a method on all types of written texts, regardless of the way research data is collected [21,22]. Additionally, this type of analysis contributes significantly to a deeper understanding of human perceptions and experiences [21,22].

The open-ended written questions method of analysis directly influenced the depth of analysis and determined the manifest approach in this study [34].

The open coding procedures in the study were performed by three researchers (the authors of this article with experience in qualitative data processing). Thus, following the steps of Elo and Kyngäs [22], researchers independently and inductively created codes, sub-categories, generic categories, and main categories. This form of triangulation has been applied to minimize the effect when multiple researchers draw different conclusions based on different data [29]. According to Elo and Kyngäs [22], at least two people need to analyze and encode data independently and separately from each other. After completing individual data analyses, the next step is to jointly achieve a definitive organization of data, so a common consensus could be ultimately reached [34]. In accordance with the research questions and analytic framework, we applied a model of inductive thematic saturation of the data with a focus on the identification of codes/themes [30].

\subsection{Ethical Considerations}

All participants were informed about the details of the study. Participation in the study was voluntary, and students could withdraw from the study without any consequences. The anonymity of participants was guaranteed. To ensure confidentiality, participants were provided with an encrypted code. Only researchers had access to research data. The study was conducted following the Declaration of Helsinki. Ethical Committee of the Faculty of Dental Medicine and Health in Osijek approved this study (IRB approval number: 2158/97-97-07-20-06). 


\section{Results}

The final organization of the data defines a total of 29 codes, 11 sub-categories (SC), and four generic categories (GC) within the two main categories (MC): (1) students' perceptions of the COVID-19 crisis, and (2) students' experiences while studying during the global COVID-19 pandemic (Table 1).

\subsection{Students' Perceptions of the COVID-19 Crisis}

Participants described in their reports the current crisis in the country, based on their perceptions of the efficiency of the state institutions, the plausibility of information systems and modes of behavior of the population during the COVID-19 crisis (GC: "state institutions and population in the COVID-19 crisis") (Table 1). Thus, 21 participants believe that state institutions are implementing effective infection control measures (SC: "actions of state institutions"). For example, the students affirmed:

"Our national government is successfully protecting its population. They properly regulate and control isolation measures"

(P. 7).

"Institutions provide useful guidance on how to suppress COVID-19"

(P. 2).

However, 12 participants felt that interventions of government institutions were delayed and insufficient, e.g.,

"More rigorous measures should be taken immediately, state borders closed and quarantine declared. Now, it is too late"

(P. 9).

"There are long rows of people in front of pharmacies which lack medications, face masks, or medical gloves. We are not well-prepared for this crisis".

(P. 21).

Twenty-three participants hold that state institutions are effectively informing the general population about the crisis (SC: "population information"), e.g.,

"Praise to the Coronavirus Crisis Management Team for frequent and proper public informing on TV networks"

(P. 3).

However, 9 participants doubt the accuracy of the information provided, e.g.,

"I don't think the population is getting accurate data on the actual numbers of infected and deceased. It may be a panic prevention measure"

(P. 31) 
Table 1. The process of data abstraction contained in the students' reports.

\begin{tabular}{|c|c|c|c|}
\hline MC & Generic Categories & Sub-Categories & Codes (Frequency of Statements) \\
\hline \multirow{6}{*}{$\begin{array}{l}\text { Students'perceptions of the global } \\
\text { COVID-19 pandemic }\end{array}$} & \multirow{3}{*}{$\begin{array}{l}\text { State institutions and the population in } \\
\text { the COVID-19 crisis }\end{array}$} & Actions of state institutions & $\begin{array}{c}\text { - Effective population protection } \\
\text { measures (21) } \\
\text { - Delayed and insufficient population } \\
\text { protection measures (12) } \\
\text { - Shortages of protective equipment and } \\
\text { medication in pharmacies (12) }\end{array}$ \\
\hline & & Informing the public & $\begin{array}{l}\text { - An efficient system of informing the } \\
\text { public (23) } \\
\text { - Doubtful veracity of the information } \\
\text { provided by state institutions (9) } \\
\text { - Spread of misinformation through } \\
\text { media and social networks (33) }\end{array}$ \\
\hline & & Population behavior & $\begin{array}{l}\text { - The gravity of the situation is not taken } \\
\text { seriously (21) } \\
\text { - Inappropriate and risky behavior of the } \\
\text { population (21) }\end{array}$ \\
\hline & \multirow{3}{*}{ Students in the COVID-19 crisis } & Emotions and opinions of students & $\begin{array}{c}\text { - Fear of the COVID-19 infection (19) } \\
\text { - Concerns for the senior members of the } \\
\text { family (33) } \\
\text { - Influence of human factors and } \\
\text { technology on the spread of disease (5) }\end{array}$ \\
\hline & & $\begin{array}{l}\text { The behavior of students and their } \\
\text { sources of information }\end{array}$ & $\begin{array}{l}\text { - Applying prevention procedures to } \\
\text { control the infection (30) } \\
\text { - Using only reliable sources of } \\
\text { information (32) }\end{array}$ \\
\hline & & Students' value systems and beliefs & $\begin{array}{l}\text { - Awareness of the responsibility } \\
\text { towards the community (23) } \\
\text { - Recognizing the benefits of the human } \\
\text { communion (23) } \\
\text { - Recognizing the importance and risks of } \\
\text { the nursing profession (23) }\end{array}$ \\
\hline
\end{tabular}


Table 1. Cont

\begin{tabular}{|c|c|c|c|}
\hline MC & Generic Categories & Sub-Categories & Codes (Frequency of Statements) \\
\hline \multirow{5}{*}{$\begin{array}{l}\text { Students'experiences while studying } \\
\text { during the global COVID-19 pandemic }\end{array}$} & \multirow{3}{*}{ Experiences with student life activities } & Public transportation services & $\begin{array}{l}\text { - Avoid using public transportation (14) } \\
\text { - Non-compliance of passengers with } \\
\text { prescribed protection measures (14) }\end{array}$ \\
\hline & & Residence in a student dormitory & $\begin{array}{c}\text { - Restriction of socializing and learning } \\
\text { with friends (3) } \\
\text { - Feeling uneasy about social distancing } \\
\text { of students (3) }\end{array}$ \\
\hline & & Teaching and learning process & $\begin{array}{l}\text { - Mild fear of becoming infected in the } \\
\text { classroom (5) } \\
\text { - Severe fear of becoming infected in the } \\
\text { clinical setting (15) } \\
\text { - Learning difficulties (13) } \\
\text { - Professionalism, courage and humanity } \\
\text { of the teachers (33) }\end{array}$ \\
\hline & \multirow{2}{*}{$\begin{array}{l}\text { Experiences with the organization of } \\
\text { work at the faculty }\end{array}$} & Teaching activities of the faculty & $\begin{array}{l}\text { - Supporting the suspension of the } \\
\text { classroom and clinical activities (33) } \\
\text { - Satisfaction with distance learning (33) }\end{array}$ \\
\hline & & Preventative measures & $\begin{array}{l}\text { - The important role of the faculty in } \\
\text { preventing the spread of infection ( } 30) \\
\text { - Effective protective measures imposed } \\
\text { by the faculty (30) }\end{array}$ \\
\hline
\end{tabular}


All participants believe that there is a massive spread of fake news and misinformation, e.g.,

"Some media, and especially social networks, are responsible for millions of fake news and misinformation, and that must be severely sanctioned"

(P. 24).

"Incredible nonsense is spreading through social networks"

(P. 12).

As many as 21 participants (SC: "population behavior") think that the population does not understand the gravity of the situation and does not follow the instructions of the Coronavirus Crisis Management Team, e.g.,

"People do not follow the instructions of the Coronavirus Crisis Team. They do not maintain a proper 2-m distance indoors, they gather and shake hands. It is self-destructive behavior"

(P. 25).

In the reports, participants also focused on their functioning in a crisis situation (GC: "students in COVID-19 crisis") (Table 1). Thus, all participants indicate a sense of concern for older members of their family (SC: "student emotions and opinions"), e.g.,

"I know that the elderly are the most vulnerable group and I worry greatly about my grandparents"

(P. 22).

Nineteen participants are truly afraid of COVID-19 infection, e.g.,

"I admit, I'm very scared of the infection"

(P. 33).

“My fear of COVID-19 is growing more intense every day, this is terrible, I can't wait for it to end"

(P. 19).

That the human factor, globalization, and modern technologies increased the spread of COVID-19 is considered by five participants, e.g.,

"It may be ironic, but 'thanks' to people and technology, especially to planes and our cellphones that we do not disinfect, the virus has spread worldwide in just a few months"

(P. 1).

As many as 30 participants describe in their reports how they constantly apply prevention procedures to control the infection (SC: "student behavior"), e.g.,

"I don't shake hands with people and I keep recommended social distance of two meters.

This is how I protect myself, but also my family and friends"

(P. 14).

"I almost always wash my hands according to the protocol, because this is the most important measure of protection"

(P. 27). 
"I always wear a face mask in the supermarket"

(P. 3.)

Twenty-three participants are trying to gather information only from relevant sources, e.g.,

"I only get information via the Internet or TV when the Coronavirus Crisis Team makes official statements"

(P. 3).

"I avoid unverified information circulating on social networks"

(P. 7).

"I follow TV news programme and official web sites of the Croatian Institute of Public Health and our university"

(P. 2).

Furthermore, 23 participants claim to be aware of their responsibility to the community, so they actively participate in volunteer activities (SC: "student values and beliefs"), e.g.,

"I want to help people because it makes me happy"

(P. 8).

"Helping people is now necessary"

(P. 17).

Additionally, the same participants claim that they recognize the importance of human communion, e.g.,

"I now see the power and importance of people uniting. Unfortunately, we need a tragedy to understand the significance and strength of community"

(P. 23).

As many as 23 participants report that during the COVID-19 crisis they recognized the true importance, responsibilities, and risks of the nursing profession, e.g.,

"I am now aware of the significance, the responsibility and the dangers of our profession.

The nurses are at extreme risk at work because of the COVID-19"

(P. 17).

"The COVID-19 crisis confirms the risks of our future profession"

(P. 8).

\subsection{Students' Experiences while Studying During the Global COVID-19 Pandemic}

Participants based their reports on experiences with public transportation services, residence in a dormitory, and teaching activities (GC: "experiences with student life activities") (Table 1). Thus, 14 participants stated that they were afraid to use public transport services (SC: "public transport services"), e.g.,

"I no longer take the bus to college because people are undisciplined and do not wear face masks"

(P. 5). 
"Now my parents drive to college because it is a risk to travel by tram"

(P. 26).

Three participants report unpleasant experiences in the student dorm (SC: "student dormitory"), e.g.,

"In the dorm, we no longer hang out with our colleagues, we eat and study separately"

(P. 15).

"I feel tense and nervous in the dormitory"

(P. 18).

Five participants reported fear of attending college classes (SC: "teaching process"), e.g.,

"It is true that only 16 cases of COVID-19 have been reported in Croatia so far, but still I am little afraid of contact with students at the faculty"

(P. 30).

"I feel a little nervous during the lectures because some students work in the hospital and are in physical contact with patients"

(P. 16).

Additionally, 15 participants reported fear of future visits to the clinical setting even after the pandemic had ceased, but they also understand the importance of clinical education, e.g.,

"I am very much afraid of future clinical training in the hospital, even after the end of the epidemic"

(P. 10).

"Hospitals sometimes do not have protective equipment for us"

(P. 7).

"I am afraid of the clinical environment, but it is a very important part of our study and I cannot wait to work with patients again"

(P. 12).

"I am afraid of becoming infected in the hospital, however, our profession is based on real clinical conditions and direct contact with patients"

(P. 3).

Significant problems with learning at home, such as lack of motivation, impaired concentration and impaired memory, have been reported in as many as 13 student reports, e.g.,

"I'm afraid of COVID-19 and I just cannot learn"

(P. 4).

"Because of this crisis I cannot concentrate, and when I study I cannot remember anything"

(P. 13).

"It is hard to learn when the lives of me and my family are at stake"

(P. 28). 
All participants praise the professionalism, courage and humanity of teachers in this crisis, e.g.,

"Our teachers are doing well, supporting and encouraging us, even though they are at risk of infection"

(P. 11).

"Teachers fully understand our fears"

(P. 12).

Furthermore, all participants are satisfied with the organization of work at the faculty during the pandemic (GC: "experience with the organization of work at the faculty") (Table 1) and support the planned temporary suspension of regular teaching activities (SC: "faculty teaching activities"), e.g.,

"The faculty is functioning great in this COVID-19 crisis"

(P. 8).

"I support the official decision to suspend classroom teaching soon and to start distance education"

(P. 12).

"Online teaching during the COVID-19 crisis is a lifesaver for us"

(P. 1).

As many as 30 students think that the faculty has an important preventive role and successfully implements the COVID-19 prevention measures (SC: "infection prevention measures"), e.g.,

"The faculty really cares about our safety. We have a lot of hand disinfectants and protective equipment here"

(P. 6).

"The faculty is important in controlling the spread of viral infection because it carries out continuous education on prevention measures, and suspension of classroom teaching and clinical training is a strong and effective preventive measure"

(P. 17).

\section{Discussion}

According to research questions, our aims were the following: (1) to describe students' perceptions of the COVID-19 pandemic, and (2) to describe students' experiences while studying during the COVID-19 pandemic.

\subsection{Students' Perceptions of the COVID-19 Crisis}

Participants focused their perceptions largely on the topics of the efficiency of state institutions and the behavior of the population during the COVID-19 crisis (GC: "state institutions and the behavior of the population during the COVID-19 crisis"). Thus, according to reports submitted by 21 participants, state institutions are implementing effective measures to control infections and protect the population. This conclusion is supported by the results of other studies [10,15], in which the majority of students agree that the authorities undertake the necessary measures for disease control, and their health education campaigns help reduce MERS-CoV transmission. In contrast, 12 participants in our study feel that the interventions of state institutions were delayed and insufficient, and that more rigorous measures should be taken, such as closing state borders and declaring quarantine. Additionally, the same 12 participants say that people were unnecessarily waiting in long rows in front of pharmacies 
that did not have enough face masks, disinfectants and medications on stock, and that a better supply of population was needed. These results indicate that participants take the situation very seriously, proposing more effective prevention of the spread of the coronavirus.

Twenty-three participants are claiming that institutions effectively inform the population about the crisis, which is consistent with the results presented in other studies $[8,10,11,15,17]$. However, 9 participants in our study believe that state institutions are hiding real data, to prevent the spread of panic amidst the population. All 33 participants report the widespread occurrence of false information (so-called "infodemia"), most commonly delivered by social media and social networks [19]. In modern times, social media can be valuable [35], but also a very risky way of informing [11].

Most participants believe that citizens are not taking the situation seriously enough and, therefore, not behaving by the recommendations of state institutions, which indicates a serious and critical approach of the nursing students involved in our study. This result is supported by Tork [17], who concluded that people are not fully aware of how the infection is transmitted. Thus, each individual's informed knowledge, attitude and behavior in crisis situation have a serious impact on the spread of infection and the safety of the entire community [36].

As many as 19 participants are suffering from an intense fear of infection, with great concern for older members of their families (GC: "students in COVID-19 crisis"). These results are supported by studies confirming that most students find coronaviruses highly contagious and fatal $[10,16,37]$. During epidemics, nursing students often experience fear and high levels of psychological distress [11,38,39]. Otherwise, fear is a positive psychological, physiological, and behavioral condition that facilitates students coping with an adverse or unexpected situation, in this case, a global pandemic [40]. So, in these extreme situations, fear is an expected and justified emotion and reflects the seriousness of participants' approach to a global problem. However, from the aspect of Aldwin's theory of stress, such crisis situations caused by natural or technological disasters, also called focal stressful events, occur suddenly and significantly threaten the mental and/or physical integrity of people [24]. Personal control over such situations is very weak.

Interestingly, five participants claim that the human factor and advanced technology contribute to the spread of COVID-19, especially the million miles of daily air passenger traffic and the frequent use of cell phones that people rarely disinfect. Participants base their interpretations on the fact that SARS-CoV-2 is highly transmissible. Thus, new scientific studies describe that SARS-CoV-2 has stability in aerosols for three hours at room temperature [2], on glass surfaces for up to two days [41], and plastic and stainless steel and up to four days [41]. Researchers conclude that SARS-CoV-2 can be highly stable in a favored environment [2], but it is also susceptible to standard disinfection methods [41].

Almost all participants adhere to the prescribed protective measures and wear face masks at indoor public spaces. This serious and professional approach of students dealing with the crisis is supported by the results of several studies [8,15]. Students are currently exposed to a variety of public and official views on the effectiveness and proper use of face masks to suppress COVID-19 transmission [42]. WHO [43] states in its published guidelines: "If you are healthy, you only need to wear a face mask if you are taking care of a person with suspected SARS-CoV-2 infection"? For example, a new study by Leung et al. [44] indicates that surgical face masks could prevent the transmission of human coronaviruses and influenza viruses from symptomatic individuals. It is striking that SARS-CoV-2 remains stable and infectious for as long as 7 days on the outer layer and 4 days on the inner layer of the surgical mask, as suggested by a new relevant study [41].

Most participants claim that they gather information only from relevant sources, via the Internet and TV. Their primary sources of information are reports from the Coronavirus Crisis Management Team, the Croatian Institute of Public Health and their home university, which is supported by other studies which state that students are informed via the Internet, TV and radio [11,15,17], or they obtain information from the faculty [11]. Additionally, participants say they ignore unverified information widely spread across social networks, which suggests their ability of critical reflection and developed media literacy. In this case, it should be considered that these are personal beliefs of students in 
an extremely stressful situation that directly threatens their lives, when there is a possibility that participants are not able to objectively assess the level of truthfulness of certain information [24]. However, earlier reports suggested that students often gather information through current social networks in crises [8,9] and find it difficult to distinguish rumors from facts [45]. According to Al-Rabiaah [11], false information can also cause severe forms of psychological tension for students.

As many as 23 participants recognize the importance of bringing people together in a crisis, they feel responsible to the community and participate in various volunteer work. Thus, participants implement a holistic approach, as primordial nursing theory, in a support context, together with their knowledge and skills [46]. Additionally, through the experience of crisis, participants recognize the true value and importance of nursing, but also the reality of high risks of the nursing profession. It is important to point out that none of the participants mentioned the possibility of quitting their studies or leaving the nursing profession in their reports. There is considerable evidence that students who experience a disparity between expectations and actual experiences are at risk of withdrawing from their studies [34]. Thus, regardless of the extreme crisis, psychological tension, fear of contagion, and the daily increase in numbers of infected and deceased healthcare professionals, participants still believe they made a good choice of their future profession. This is also supported by the students claiming that they hope to return to work with patients soon, regardless of their fear of the COVID-19. Additionally, students are aware that nurses must be competent and well prepared for these and similar crises. Therefore, nurses in these extremely crisis situations must have a unique knowledge base, abilities, and skills that are needed to respond appropriately to health care and human service needs [47]. Such students' views can be considered and elaborated using the theoretical concept of professional identity and from the aspect of humanistic nursing theories, whose philosophical deep roots are grounded in humanism, existentialism, and phenomenology [48] Thus, the identity of nurses develops throughout their professional lives, from entering into the educational system, growing during the years of their study and clinical experience, and continuing to develop throughout their careers. It is precisely the period of their higher education that is crucial, because nursing students acquire the knowledge and skills that make them a special kind of health care professionals [27].

\subsection{Students' Experiences while Studying During the Global COVID-19 Pandemic}

Participants described their experiences in the context of using public transportation services, residence in a dormitory, and regular teaching process at the university (GC: "experiences with student life activities"). Thus, 14 participants avoided using public transportation to and from faculty, as people on buses and trams did not adhere to the recommended safeguard measures. Such undisciplined behavior of people in crises is not uncommon [17], and threatens the health of the entire population [36]. Ten days after conducting this study, all public transport lines were temporarily suspended by decision of the Coronavirus Crisis Management Team.

Three participants described feeling uneasy or anxious about the measures of social distancing in the dormitory [35]. It is known that rigorous public health measures of isolation can have adverse psychological effects, such as nervousness, anger, fear, sadness, confusion, insomnia, depression, stress, etc. [49]. In contrast, Wang and associates [50], in their study, conducted on a sample of 444 students, and described how the quarantine measures prescribed to prevent the spread of H1N1 flu had no psychological effects on the students. To prevent the negative psychological impact of isolation measures, it is important to inform the population clearly and accurately, to explain the reasons and expected duration of individual events, and to secure the smooth operation of basic work activities and sufficient supplies (food, water, medications, etc.) [49].

Only five participants felt a mild fear of infection during classroom lectures, while 15 participants described high levels of fear caused by the expectation of impending departure to the clinical setting, even after the end of the pandemic. These results are supported by studies, in which most students claimed that they avoid going to the clinical setting because they are scared of contagion $[8,16]$. Such results are not surprising, as they indicate students' awareness of the pathogenicity and 
transmissibility of SARS-CoV-2 [4] and the high risk of infection in the clinical settings $[4,10,11]$. Additionally, participants are confronted with the fact that healthcare professionals around the world are becoming ill or even die because of the COVID-19. However, participants, at the same time, understand the importance of clinical education, and hope to work with patients as soon as possible. Clinical faculties in the clinical environment facilitate the student's acquisition of professional knowledge: technical, psychomotor, interpersonal, and communication skills; attitudes; professional responsibility; self-confidence; and autonomy in the clinical setting [51]. Furthermore, several participants reported occasional problems with lack of protective masks and medical gloves for nursing interns in the hospital, which is confirmed by other studies [52,53]. By exposing themselves to risks, especially in the clinical setting, nursing students can be victims of infection, and also potential transmitters of the disease to the wider population. Therefore, higher education and health care institutions around the world need to educate students on the most effective crisis management measures and continuously protect their students by providing high quality and safe clinical learning environment [9].

Due to the COVID-19 crisis, 13 participants described lack of motivation, impaired concentration and impaired memory, which made learning difficult for them. According to Al-Rabiaah [11], during epidemics, students in the health professions often suffer from decreased psychomotor concentration and learning disabilities and avoid learning activities, which can have negative implications for their academic achievement [11].

All participants in our study praise the professionalism, courage, and overall humanity of teachers in this crisis, which is very important, because it mirrors support for the students and delivers useful feedback to their teachers and higher education institutions [7]. Participants state that teachers work in accordance with the new situation, carefully adapting the curriculum, the exam literature, methods of teaching, learning outcomes, elements and evaluation criteria, helping students greatly in this crisis.

The organization of work at the faculty during the pandemic is supported by all participants (GC: "experiences with the organization of work at the faculty"). Prompt interventions of cancelling students' departures to the clinical setting, suspending classroom teaching, and initiating distance learning, are found to be proper and reasonable by the participants. Participants believe that the faculty has an important preventative role and successfully implements epidemic prevention measures, which is consistent with students' reports analyzed in other studies [16].

The results of this study, despite the application of the inductive approach, are not too surprising. The relations between the formed subcategories and categories point to the fact that students' perceptions and experiences were significantly conditioned by their physiological reactions, emotions, and fears, which further confirms the dominant influence of cognitive theories of emotions, fear, and stress underlying this study.

\subsection{Limitations of the Study}

In this qualitative study, participants included nursing students from only one Croatian university. Additionally, because the COVID-19 infection is a newly emerging pandemic, there is a lack of references to similar studies, especially regarding the experiences of nursing students, and the potential influence of the COVID-19 crisis on their study process. Therefore, the results were analyzed and discussed in comparison with relevant studies describing nursing students' experiences during an earlier MERS-CoV epidemic. Additionally, the results of the study are a reflection of the perceptions and experiences of a saturated group of respondents and cannot be generalized to include other nursing students, and especially not the students of other professions. One should certainly take into account the very specific professional identity of nursing students and the aspects of humanistic nursing theories that have led most of them to choose their profession. 


\subsection{Usefulness and Applicability of Study Results}

The results of this study provide a deeper insight into the perceptions, feelings, opinions, and experiences of nursing students during the COVID-19 pandemic. The data obtained help to identify areas of psychophysical and other needs, and recurring problems of nursing students, as well as possible difficulties in their academic functioning. Formed categories and subcategories related to classroom teaching can largely be used in understanding the perceptions and experiences of students in all academic disciplines on a global scale, because classrooms are mostly enclosed spaces where students are exposed to the risks and fear of possible infection. Furthermore, the results related to clinical training could be useful in understanding the experiences of nursing students around the world, as well as experiences of other future health care professionals (those, for example, studying medicine, physiotherapy, or biomedicine), who are, during their studies, trained in real clinical environments, in direct contact with patients and hospital staff. The theoretical basis of this study (cognitive theories of emotions, fear, and stress) allows the results to be useful in analyzing the experiences of students from different geographical areas and cultures affected by the pandemic, and possibly the experiences of their peers, regardless of their academic status. Given the rapid dynamic changes of events and the unpredictable variability of situations, which is essential to the state of every global crisis, student perceptions and experiences are very variable, and often unstable components. Therefore, in analyzing and interpreting the results of cross-sectional studies, one should be aware of the temporal (in)stability of the established data, therefore, it is necessary to conduct multiple assessments of student perceptions at different stages of crisis development. Furthermore, the study provides details that can facilitate the design of student support strategies and provide a safe learning environment. Therefore, in order to establish effective support mechanisms for students in a timely manner, it is important to have a comprehensive insight into the students' perceptions, feelings, and experiences occurring in crisis situations. Different methods in helping them include: providing psychological support to students so they can confront and control their reactions in crisis situations; providing relevant and true information for students during the crisis; protecting students from possible infection during class teaching, clinical training, and other activities that are part of their student life; applying teaching forms and methods, which will make it easier for students to learn in crisis situations; providing conditions in which students will be active factors in preventing the spread of infection, etc. Additionally, the results give useful feedback on students' perceptions of the effectiveness of actions taken by the faculty executives and teachers in this crisis situation. This study could also be an incentive for higher education institutions and the academic community to undertake similar comparative studies. In addition, the inductively formed categories in this study could be a stimulus and a possible basis for the development of newly structured instruments, and the design of further qualitative and quantitative studies. Thus, future comparative studies could cover a wider geographical area and include students of other professions, with the possibility of additional involvement of experimental and control groups of respondents, in order to strengthen the objectification and generalization of results. Finally, but equally importantly: this study expands existing global knowledge about the psychological and behavioral aspects of student functioning in crisis situations, and points to the importance of timely assessment of their perceptions and experiences during global pandemics.

\section{Conclusions}

In this study, we described students' perceptions of the COVID-19 pandemic and their experiences while studying during this global crisis. To best of our knowledge, this is the first qualitative study to describe nursing students' perceptions and experiences during the COVID-19 pandemic. The results indicate that students have somewhat divided opinions about the effectiveness of state institutions and their information policies. All students are describing the dissemination of misinformation through social networks and seek to use only relevant sources of information. Most students describe the high-risk behavior of the population during the COVID-19 crisis. Fear of contagion and concern for family members is common in all students, which is why they adhere to the instructions given by state 
institutions and continuously implement measures to control the spread of the infection. During the crisis, most of them became aware of their responsibility to the community and recognized the true importance and risks of the nursing profession. Students feel a mild fear of being infected during classroom teaching, but they are very afraid of future visits to the clinical setting. However, they are aware of the importance of working in a realistic clinical environment, directly with patients, to acquire professional competencies. Through student perceptions, emotions, and experiences, one can sense the impact of the theoretical concept of professional identity in nursing and humanistic nursing theories. Due to the crisis, participants describe their lack of motivation, poor concentration, and significant learning difficulties. The organization of work at the faculty, and the efforts of teachers in this crisis are assessed as being very effective. Students fully support the plans for long-distance teaching, and see the postponement of clinical internship as a life-saving solution. They also hold that the faculty is effectively implementing measures aimed at the protection of students, teachers, and the wider community.

Author Contributions: Conceptualization, R.L.; Data curation, N.F. and S.M.; Investigation, R.L., N.F., S.M. and A.V.; Methodology, R.L. and N.F.; Resources, S.M. and A.V.; Supervision, R.L. and N.F.; Validation, R.L., N.F., S.M. and A.V.; Visualization, S.M. and A.V.; Writing-original draft, R.L., N.F. and A.V.; Writing-review \& editing, R.L., N.F. and S.M. All authors have read and agreed to the published version of the manuscript.

Funding: This research received no external funding.

Conflicts of Interest: The authors declare no conflict of interest.

\section{References}

1. Spagnuolo, G.; De Vito, D.; Rengo, S.; Tatullo, M. COVID-19 outbreak: An overview on dentistry. Int. J. Environ. Res. Public Health 2020, 17, 2094. [CrossRef]

2. Van Doremalen, N.; Bushmaker, T.; Morris, D.H.; Holbrook, M.G.; Gamble, A.; Williamson, B.N.; Tamin, A.; Harcourt, J.L.; Thornburg, N.J.; Gerber, S.I.; et al. Aerosol and surface stability of SARS-CoV-2 as compared with SARS-CoV-1. N. Engl. J. Med. 2020. [CrossRef]

3. World Health Organization (WHO). Coronavirus Disease (COVID-19) Outbreak Situation. Available online: https://www.who.int/emergencies/diseases/novel-coronavirus-2019 (accessed on 15 March 2020).

4. Han, Y.; Yang, H. The transmission and diagnosis of 2019 novel coronavirus infection disease (COVID-19): A Chinese perspective. J. Med. Virol. 2020. [CrossRef]

5. Liu, Y.; Yan, L.-M.; Wan, L.; Xiang, T.-X.; Le, A.; Liu, J.-M.; Peiris, M.; Poon, L.L.; Zhang, W. Viral dynamics in mild and severe cases of COVID-19. Lancet Infect. Dis. 2020. [CrossRef]

6. Zou, L.; Ruan, F.; Huang, M.; Liang, L.; Huang, H.; Hong, Z.; Yu, J.; Kang, M.; Song, Y.; Xia, J.; et al. SARS-CoV-2 viral load in upper respiratory specimens of infected patients. N. Engl. J. Med. 2020, 382, 1177-1179. [CrossRef] [PubMed]

7. Park, S.W.; Jang, H.W.; Choe, Y.H.; Han, B.K.; Ahn, Y.C.; Chung, M.J.; Lee, K.-S.; Lee, K.; Han, T. Avoiding student infection during a Middle East respiratory syndrome (MERS) outbreak: A single medical school experience. Korean J. Med. Educ. 2016, 28, 209-217. [CrossRef]

8. Elrggal, M.E.; Karami, N.A.; Rafea, B.; Alahmadi, L.; Al Shehri, A.; AlAmoudi, R.; Koshak, H.; Alkahtani, S.; Cheema, E. Evaluation of preparedness of healthcare student volunteers against MERS-CoV in Makkah, Saudi Arabia: A cross-sectional study. J. Public Health 2018, 26, 607-612. [CrossRef] [PubMed]

9. Stirling, B.V.; Harmston, J. Readying nurses for clinical practice: Protecting students during an outbreak of Middle Eastern-Coronavirus in Saudi Arabia. J. Nurs. Educ. Pract. 2015, 5, 40-44. [CrossRef]

10. Asaad, A.M.; El-Sokkary, R.H.; Aedh, A.I.; Alamanan, M.A.A.; Khalil, F.O. Exploring knowledge and attitude toward Middle East Respiratory Syndrome-Coronavirus (MERS-CoV) among university health colleges' students, Saudi Arabia: A cross-sectional study. Am. J. Infect. Dis. 2019, 15, 37-43. [CrossRef]

11. Al-Rabiaah, A.; Temsah, M.-H.; Al-Eyadhy, A.A.; Hasan, G.M.; Al-Zamil, F.; Al-Subaie, S.; Al-Sohime, F.; Jamal, A.; Alhaboob, A.; Al-Saadi, B.; et al. Middle East Respiratory Syndrome-Corona Virus (MERS-CoV) associated stress among medical students at a university teaching hospital in Saudi Arabia. J. Infect. Public Health 2020. [CrossRef] 
12. World Health Organization (WHO). Coronavirus Disease 2019 (COVID-19) Situation Report-82. Subject in Focus: Infection in Health Care Workers. Available online: https://www.who.int/docs/default-source/ coronaviruse/situation-reports/20200411-sitrep-82-covid-19.pdf?sfvrsn=74a5d15_2 (accessed on 31 March 2020).

13. Kim, J.S.; Choi, J.S. Middle East respiratory syndrome-related knowledge, preventive behaviors and risk perception among nursing students during outbreak. J. Clin. Nurs. 2016, 25, 2542-2549. [CrossRef] [PubMed]

14. Centers for Disease Control and Prevention (CDC). Severe respiratory illness associated with a novel coronavirus-Saudi Arabia and Qatar, 2012. MMWR Morb. Mortal. Wkly. Rep. 2012, 61, 820.

15. Hassan, H.M. Knowledge and attitude of Al-Ghad college students towards corona virus infection. January. Int. J. Med. Res. 2016, 4, 19-26. [CrossRef]

16. Al-Hazmi, A.; Gosadi, I.; Somily, A.; Alsubaie, S.; Bin Saeed, A. Knowledge, attitude and practice of secondary schools and university students toward Middle East Respiratory Syndrome epidemic in Saudi Arabia: A cross-sectional study. Saudi. J. Biol. Sci. 2018, 25, 572-577. [CrossRef]

17. Tork, H.M.M.; Mersal, F.A. Middle East Respiratory Syndrome-Corona virus: Knowledge and attitude of Qassim University students, KSA. Glob. Adv. Res. J. Med. Med. Sci. 2018, 7, 90-97.

18. Kim, M.-J. The convergence study of nursing students' knowledge, attitudes and preventive behaviors against MERS in South Korea. J. Korea Converg. Soc. 2017, 8, 149-157. [CrossRef]

19. Zarocostas, J. How to fight an infodemic. Lancet 2020, 395, 676. [CrossRef]

20. World Health Organization (WHO). Coronavirus Disease 2019 (COVID-19). Situation Report-53. Available online: https://www.who.int/docs/default-source/coronaviruse/situation-reports/20200313-sitrep-53-covid19.pdf?sfvrsn=adb3f72_2 (accessed on 15 March 2020).

21. Hsieh, H.F.; Shannon, S.E. Three Approaches to Qualitative Content Analysis. Qual. Health Res. 2005, 15, 1277-1288. [CrossRef]

22. Elo, S.; Kyngäs, H. The qualitative content analysis process. J. Adv. Nurs. 2008, 62, 107-115. [CrossRef]

23. Oatley, K.; Johnson-laird, P.N. Towards a Cognitive Theory of Emotions'. Cogn. Emot. 1987, 1, 29-50. [CrossRef]

24. Aldwin, C.M. Stress, Coping, and Development: An Integrative Perspective, 2nd ed.; The Guilford Press: New York, NY, USA, 2009.

25. Stevens, R.; Erik, H. Erikson: Explorer of Identity and the Life Cycle; Palgrave Macmillan: New York, NY, USA, 2008.

26. Holland, J.J.; Johnston, J.; Asama, N. The Vocational Identity Scale: A diagnostic and treatment tool. J. Career. Assess. 1993, 1, 1-12. [CrossRef]

27. Johnson, M.; Cowin, L.S.; Wilson, I.; Young, H. Professional Identity and Nursing: Contemporary Theoretical Developments and Future Research Challenges. Int. Nurs. Rev. 2012, 59, 562-569. [CrossRef] [PubMed]

28. Palinkas, L.A.; Horwitz, S.M.; Green, C.A.; Wisdom, J.P.; Duan, N.; Hoagwood, K. Purposeful sampling for qualitative data collection and analysis in mixed method implementation research. Adm. Policy Ment. Health 2015, 42, 533-544. [CrossRef]

29. Bengtsson, M. How to plan and perform a qualitative study using content analysis. Nurs. Plus. Open. 2016, 2, 8-14. [CrossRef]

30. Saunders, B.; Sim, J.; Kingstone, T.; Baker, S.; Waterfield, J.; Bartlam, B.; Burroughs, H.; Jinks, C. Saturation in qualitative research: Exploring its conceptualization and operationalization. Qual. Quant. 2018, 52, 1893-1907. [CrossRef]

31. Sandelowski, M. Sample size in qualitative research. Res. Nurs. Health 1995, 18, 179-183. [CrossRef]

32. Mason, M. Sample size and saturation in $\mathrm{PhD}$ studies using qualitative interviews. Forum Qual. Health Res. 2010, 11, 8. [CrossRef]

33. Polit, D.F.; Beck, C.T. Nursing Research: Generating and Assessing Evidence for Nursing Practice, 9th ed.; Lippincott Williams \& Wilkins: Philadelphia, PA, USA, 2012.

34. Lovrić, R.; Prlić, N.; Milutinović, D.; Marjanac, I.; Žvanut, B. Changes in nursing students' expectations of nursing clinical faculties' competences: A longitudinal, mixed-methods study. Nurse Educ. Today 2017, 59, 38-44. [CrossRef]

35. Wilder-Smith, A.; Freedman, D.O. Isolation, quarantine, social distancing and community containment: Pivotal role for old-style public health measures in the novel coronavirus (2019-nCoV) outbreak. J. Travel. Med. 2020, 27. [CrossRef] 
36. Akan, H.; Gurol, Y.; Izbirak, G.; Ozdatlı, S.; Yilmaz, G.; Vitrinel, A.; Hayran, O. Knowledge and attitudes of university students toward pandemic influenza: A cross-sectional study from Turkey. BMC Public Health 2010, 10, 1-8. [CrossRef]

37. Khan, M.U.; Shah, S.; Ahmad, A.; Fatokun, O. Knowledge and attitude of healthcare workers about Middle East Respiratory Syndrome in multispecialty hospitals of Qassim, Saudi Arabia. BMC Public Health 2014, 14, 1281. [CrossRef]

38. Wong, J.G.; Cheung, E.P.; Cheung, V.; Cheung, C.; Chan, M.T.; Chua, S.E.; McAlonan, G.; Tsang, K.W.; Ip, M.S.M. Psychological responses to the SARS outbreak in healthcare students in Hong Kong. Med. Teach. 2004, 26, 657-659. [CrossRef]

39. Khalid, I.; Khalid, T.J.; Qabajah, M.R.; Barnard, A.G.; Qushmaq, I.A. Healthcare workersemotions, perceived stressors and coping strategies during a MERS-CoV out-break. Clin. Med. Res. 2016, 14, 7-14. [CrossRef] [PubMed]

40. Steimer, T. The biology of fear- and anxiety-related behaviors. Dialogues Clin. Neurosci. 2002, 4, 231-249.

41. Chin, A.W.H.; Chu, J.T.S.; A Perera, M.R.; Hui, K.P.Y.; Yen, H.-L.; Chan, M.C.W.; Peiris, M.; Poon, L.L.M. Stability of SARS-CoV-2 in different environmental conditions. Lancet Microbe. 2020. [CrossRef]

42. Feng, S.; Shen, C.; Xia, N.; Song, W.; Fan, M.; Cowling, B.J. Rational use of face masks in the COVID-19 pandemic. Lancet Respir. Med. 2020. [CrossRef]

43. World Health Organization (WHO). Coronavirus Disease (COVID-19) Advice for the Public: When and How to Use Masks. Available online: https://www.who.int/emergencies/diseases/novel-coronavirus-2019/ advice-for-public/when-and-how-to-use-masks (accessed on 2 April 2020).

44. Leung, N.H.L.; Chu, D.K.W.; Shiu, E.Y.C.; Chan, K.-H.; McDevitt, J.J.; Hau, B.J.P.; Yen, H.-L.; Li, Y.; Ip, D.K.M.; Peiris, J.S.M.; et al. Respiratory virus shedding in exhaled breath and efficacy of face masks. Nat. Med. 2020. [CrossRef] [PubMed]

45. Stirling, B.V.; Harmston, J.; Alsobayel, H. An educational programme for nursing college staff and students during a MERS- coronavirus outbreak in Saudi Arabia. BMC Nurs. 2015, 14, 20. [CrossRef] [PubMed]

46. Fukada, M. Nursing competency: Definition, structure and development. Yonago Acta Med. 2018, 61, 1-7. [CrossRef]

47. Lavin, R.P.; Adelman, D.S.; Veenema, T.G. Society for the Advancement of Disaster Nursing: Exploring the Path to Excellence. Disaster Med. Public Health Prep. 2017, 11, 641-646. [CrossRef]

48. Paterson, J.G.; Zderad, L.T. Humanistic Nursing; John Wiley \& Sons: New York, NY, USA, 1976.

49. Brooks, S.K.; Webster, R.K.; E Smith, L.; Woodland, L.; Wessely, S.; Greenberg, N.; Rubin, G.J. The psychological impact of quarantine and how to reduce it: Rapid review of the evidence. Lancet 2020, 395, 912-920. [CrossRef]

50. Wang, Y.; Xu, B.; Zhao, G.; Cao, R.; He, X.; Fu, S. Is quarantine related to immediate negative psychological consequences during the 2009 H1N1 epidemic? Gen. Hosp. Psychiatry 2011, 33, 75-77. [CrossRef] [PubMed]

51. Lovrić, R.; Prlić, N.; Zec, D.; Pušeljić, S.; Žvanut, B. Students' assessment and self-assessment of nursing clinical faculty competencies: Important feedback in clinical education? Nurse. Educ. 2015, 40, E1-E5. [CrossRef] [PubMed]

52. Jeong, I.; Cho, J.; Park, S. Compliance with standard precautions among operating room nurses in South Korea. Am. J. Infect. Control. 2008, 36, 739-742. [CrossRef]

53. Choi, J.S.; Kim, J.S. Factors influencing preventive behavior against Middle East Respiratory Syndrome-Coronavirus among nursing students in South Korea. Nurse Educ. Today 2016, 40, 168-172. [CrossRef]

(C) 2020 by the authors. Licensee MDPI, Basel, Switzerland. This article is an open access article distributed under the terms and conditions of the Creative Commons Attribution (CC BY) license (http://creativecommons.org/licenses/by/4.0/). 